\title{
AMBIENTALIZAÇÃO CURRICULAR: O DESENVOLVIMENTO PESSOAL E PROFISSIONAL DE PROFESSORES DA EDUCAÇÃO BÁSICA
}

\section{RESUMO}

\author{
ARRUDA,Dra Marina Patrício de/UNIPLAC ${ }^{1}$ \\ LIMA, Dra Lucia Cecatto de /UNIPLAC ${ }^{2}$
}

\begin{abstract}
A Universidade como instituição formadora de professores apresenta-se como espaço importante na consolidação de outra proposição pedagógica de Educação ambiental, processo que poderia incluir as dimensões do desenvolvimento pessoal e profissional de professores da Educação Básica. Buscando criar possibilidades para uma reforma do pensamento de professores de um Centro de Educação Infantil Municipal, uma experiência de pesquisação foi desenvolvida com o objetivo de ampliar o debate sobre a Educação Ambiental e a Ambientalização nos currículos da Educação Básica. As histórias de vida orais obtidas indicaram a escola como espaço de formação não só para os alunos, mas, também para os professores sobre a questão ambiental. Concluímos provisoriamente que os encontros pedagógicos promoveram a compreensão da relação entre Educação Ambiental, Ambientalização e Educação para a Inteireza contribuindo para com o processo de desenvolvimento pessoal e profissional daqueles professores. E nessa aventura reflexiva, os professores puderam pensar num outro modelo de formação integral capaz de privilegiar o reconhecimento do caráter multidimensional do humano.
\end{abstract}

Palavras-chave:Desenvolvimento Profissional e Pessoal. Educação Ambiental. Ambientalização curricular. Professores da Educação Básica.

\section{INTRODUÇÃO}

Com o propósito de ampliar o debate sobre a Educação Ambiental e a Ambientalização dos currículos da Educação Básica um projeto de pesquisa e extensão intitulado: "Educação para Inteireza: desenvolvimento profissional e pessoal dos professores da educação básica" foi desenvolvido junto a professores de um Centro de Educação Infantil Municipal (CEIM). Os encontros alternaram estratégias de Educação Permanente (EP) e de Educação Continuada $(E C)^{3}$ que associadas à discussão sobre Educação ambiental visaram ampliar as possibilidades de compreensão dos professores sobre a necessidade dessa formação tendo como base a relação do homem e meio ambiente. Essa ação, vinculada ao Grupo de Pesquisa em Educação Saúde e Qualidade de Vida - GEPESVIDA objetivou discutir também as possibilidades 
de uma Educação para Inteireza cujas reflexões resultam dos estudos de Wilber (2007).

A relevância dos aspectos da experiência, dos contornos da consciência, "disponíveis na própria concepção de cada um e que necessitam ser explorados, estudados, compreendidos para que possam nos auxiliar a nos conhecermos (autoconhecimento)" (PORTAL, 2007, p. 290) indica a necessidade de nos compreendermos como seres de inteireza. Esse desafio nos coloca frente a urgência em se oferecer pontos de referência que contribuam com Programas informais e formais em nível de graduação e pósgraduação que discutam a importância do desenvolvimento de diferentes dimensões - físico, emocional, intelectual e espiritual do docente. Nesse sentido, identificamos na experiência com os professores da Educação Básica reflexões que retroalimentam nosso pensamento rumo à Ambientalização curricular e educação ambiental.

A pesquisação, aqui mencionada, foi adotada para o estudo por pressupor, segundo Thiollent (1997, p. 36), uma concepção de ação, que "requer, no mínimo, a definição de vários elementos: um agente (ou ator), um objeto sobre o qual se aplica a ação, um evento ou ato, um objetivo, um ou vários meios, um campo ou domínio delimitado". Uma pesq1uisa participativa realizada em estreita associação entre pesquisador e participantes, sob uma ação coletiva cooperativa e emancipatória.

Essas estratégias metodológicas criaram possibilidades para uma mudança e reforma de pensamento (MORIN, 2010) de professores de um Centro de Educação Infantil Municipal da cidade de Lages SC. Essa proposta demandou um esforço de complexidade pessoal e profissional de professores universitários e de todos profissionais da Educação que lá se encontravam buscando pensar outro modelo de formação profissional capaz de privilegiar o reconhecimento do caráter multidimensional da sociedade e do humano.

\section{DESENVOLVIMENTO PESSOAL E PROFISSIONAL DE PROFESSORES}


A questão da educação ambiental surge como uma ação estratégica para a educação capaz de "reformar o pensamento" das pessoas para o cuidado consigo, com o outro e com a natureza. Para Morin, "Este novo casamento entre a natureza e a humanidade necessitará, sem dúvida, como acabamos de dizer, de uma superação da técnica atual que por sua vez necessita de uma superação do modo de pensar atual, inclusive, científico." (2001, p. 94). Assim, convém destacar que a crise ambiental compreendida como uma crise da racionalidade instrumental (LEFF, 2001) segue espalhando seus efeitos sobre o ambiente natural, em relação à preservação da vida e da biodiversidade, ameaçadas pelo modelo capitalista de produção, consumo e descarte. Desse modo, a Universidade como instituição promotora e formadora de professores, apresenta-se como espaço importante na consolidação de outra proposição pedagógica de cuidado ambiental.Esse processo, conforme aponta Zabalza (2004), deveria incluir o desenvolvimento pessoal, principalmente aqueles com possibilidade de recuperação da auto-estima bem como o enriquecimento das experiências vivenciadas. Assim, a formação continuada de professores também envolveria diferentes cenários que contemplariam as dimensões: pessoais, sociais e profissionais.

No processo de formação de professores as licenciaturas e/ou os cursos de Pedagogia carecem de caminhos para formar professores dentro de uma perspectiva que alie teoria e a prática. Segundo Behrens (1996, p.124):

\footnotetext{
Elas precisam interpenetrar-se, interligar-se, possibilitando ao profissional conhecimento e atuação numa realidade concreta. $\mathrm{O}$ compromisso visado é o profissional envolvido com a práxis, que acredite na investigação como um caminho ininterrupto a ser conquistado na busca da competência docente, e na predisposição para a transformação da prática à luz da teoria.
}

Com essa perspectiva, docência dentro de uma visão complexa articula teoria e a prática numa ação transformadora cuja prática pedagógica contempla aprendizagens para vida.

Considerar o desenvolvimento pessoal e profissional de professores, pelo entendimento de Porto (2000, p.14), se dá quando o "fazer, entendido como uma atividade alheia à experiência e ao conhecimento do professor cede 
lugar ao saber fazer reflexivo, entendido como autoformação", caminho que mostra a indissociabilidade entre teoria e prática.

Com a Resolução de $N^{\circ}$ 2/2012 do Conselho Nacional de Educação (CNEA Conselho Pleno) entra em vigor as Diretrizes Curriculares Nacionais para a educação Ambiental (EA). Essas Diretrizes determinam que aos sistemas de ensino promovam condições para que suas instituições educacionais se constituam em:

[...] espaços educadores sustentáveis, com a intencionalidade de educar para a sustentabilidade socioambiental de suas comunidades, integrando currículos, gestão e edificações, em relação equilibrada com o meio ambiente e tornando-se referência para seu território (BRASIL, CNE, 2012, p. 7).

Mas, como promover conhecimentos concernentes à EA nos currículos da educação básica considerando que os professores ainda não se encontram preparados para esse compromisso? Como reformar o pensamento dos professores para a Ambientalização Curricular?

A ambientalização Curricular é um conhecimento novo e desafiador. "Segundo a Política Nacional de Educação Ambiental, no ensino superior é facultada a criação de disciplinas nas áreas voltadas aos aspectos metodológicos da Educação Ambiental (EA), nos cursos de pós-graduação e de extensão" (ZUIN et al, 2009). Essa política asseguraria um caminho para essa implementação, mas como tema transversal e interdisciplinar essa proposta depende também de discussões mais amplas sobre os currículos da educação básica e superior incluindo a formação dos professores. A ambientalização nos desafia a exercitar a Educação Ambiental dentro dos curriculos/ disciplinas.

Em acordo com Kitzmann\&Amus (2012, p. 270): "Ambientalização curricular surge para institucionalizar a educação ambiental (EA) no ensino superior". Essa indicação nos faz refletir a importância do educar-se por inteiro integrando disciplinas que conjuguem esse conhecimento no debate sobre a Ambientalização nos currículos da Educação Básica.

Ambientalização Curricular seria como um processo contínuo de produção cultural “(...) voltado à formação de profissionais comprometidos com 
a busca permanente das melhores relações possíveis entre a sociedade e a natureza, atendendo aos valores da justiça, solidariedade e da equidade [...] (REDE ACES, 2000).

Isto posto, torna-se oportuno e necessário aprofundar essa discussão para contribuir no desenvolvimento pessoal e profissional dos docentes tendo em vista processos educativos das crianças, especialmente aqueles vinculados à educação ambiental, contexto que nos coloca em meio a vários questionamentos, afinal como promover conhecimentos e experiências concernentes à Educação Ambiental e a AmbientalizaçãoCurrícular dos professores da Educação Básica? Como prepará-los e apoiá-los para esse compromisso?

O GEPESVida como grupo de investigação e reflexão investiu num processo cuja "aprendizagem passa a ter foco na visão complexa do universo e na educação para vida" (BEHRENS, 2006, p.14), por acreditar na formação de sociedades mais justas e ecologicamente equilibradas, e no professor como elemento de decisão para uma Educação para Inteireza. Esse termo utilizado por Morin (2003), Portal (2006), Wilber (2007) e Andrade (2011) diz respeito à "Qualidade do que é inteiro" e considera que a educação não pode mais seguir fragmentada produzindo consciências reducionistas e desprezando as mais variadas dimensões humanas em nome de uma ciência que priorizou a parte em detrimento do todo. Nesse sentido, a ambientalização Curricular surge como um novo paradigma de Educação.

\section{ANÁLISE E TRATAMENTO DOS DADOS}

A partir das histórias de vida orais dos professores do CEIM onde foi realizado o estudo emergiram dois eixos de análise: Experiências da infância e Atitudes conscientes sobre educação ambiental.

\subsection{EXPERIÊNCIAS DA INFÂNCIA}

Criar Educação, Criciúma, v. 6, n², julho/novembro 2017.- PPGE - UNESC 

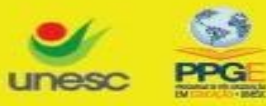

Nessa categoria, a que chamamos de eixo, optamos em analisar as memórias das experiências da infância dos educadores do CEIM resgatando as influências na trajetória de vida e os momentos cruciais que parecem relacionados à Educação Ambiental. As histórias de vida orais elencadas mostram que os professores relembraram suas histórias e tentaram detectar nelas os fatos marcantes que promoveram seu interesse pela questão ambiental, como é possível perceber a seguir:

"[...] memórias da minha infância [...] Lembro-me perfeitamente das suas atitudes relacionadas a economia da água, o cuidado com os objetos jogados no campo, [...] ele tinha a sabedoria para cuidar do espaço, defender a natureza nas diferentes situações" (P1)

"Desde criança percebo que minha família não está ligada a preservação da natureza, separação de resíduos ou por exemplo: economizar água." (P3)

"Na minha infância não existia preocupação com o meio ambiente, brincávamos livres em contato com a natureza e todos as belezas nela contida". (P7)

"Meus familiares principalmente avós me incentivavam a plantar flores, a limpar o terreno, cuidar dos animais, esteja onde eu estiver. Ficava feliz quando viajava e observava os campos verdes e animais pastando. Ou até mesmo quando ia visitar o sítio do meu vô. Dentro de casa minha mãe sempre plantava em vasos folhagens e flores. Do lado de fora, no terreno cuidava do lindo gramado com vários pés de roseiras, já meu pai não posso falar a mesma coisa. Até hoje ele não é muito afim". (P9)

O desenvolvimento pessoal e profissional dos professores emerge das histórias de vida orais entrelaçadas e marcadas por uma processualidade desde a infância até a vida adulta com espaços e tempos influenciados em defesa do ambiente e suas particularidades narradas, que se conta a sua visão sobre a sua história vivida (NÓVOA, 2007; GOODSON, 2007; MOITA, 2007; JOSSO, 2010).

Nesse sentido, como Nóvoa (2007) e demais defensores da História Oral de Vida, fundamentam suas abordagens nas pesquisas (auto)biográficas como possibilidade de identificar nesse professor características de desenvolvimento profissional e pessoal. Assim, as histórias orais de vida das professoras entrevistadas expunham uma linha tênue entre passado e presente. A história oral de vida é cheia de detalhes e significados construídos pelos mesmos a cerca de suas experiências.

As narrativas de histórias orais pessoais e a profissionais, nem sempre claras misturam passado e presente. O que se pensa hoje sobre Educação 
Ambiental e o tempo vivido junto à família. Ao desvelarem suas histórias, revivem conceitos e práticas estabelecendo sua própria escuta para uma reflexão. As histórias de vida orais a seguir elucidam e relacionam a questão da Educação Ambiental ;

"Eu sempre soube que tinha que cuidar do Meio Ambiente. Quando era criança via fazerem as queimadas para a nova plantação, aquela fumaça se perdia no ar, aquilo era triste, eu ouvia os mais velhos falarem que no mês de agosto é um mês triste, talvez seja por isso, a natureza fica triste." (P10)

"A Educação Ambiental entrou na vida muito cedo, desde criança meus pais me mostraram o que é certo e errado, em relação ao ambiente em que vivemos, cresci em uma sociedade em que o aquecimento global e ações causadas pelo homem era uma questão muito forte, foi então que procurei estudar e compreender mais sobre o assunto" (P13)

Essas duas histórias de vida orais revelam ensinamentos fundamentais advindos da infância e sinalizam algumas semelhanças que nos parecem ser relevantes para a compreensão da necessidade de se retomar histórias orais sobre os aspectos "familiares e da infância" dos educadores. O tempo de queimar os campos como uma prática natural e ao mesmo tempo triste, os ensinamentos, a necessidade se aprofundar seus conhecimentos. Para Bosi (2003, p. 62), "[...] quando se trata de história recente, feliz o pesquisador que se pode amparar em testemunhos vivos e reconstruir atitudes e sensibilidades de uma época!"

Maturana (1986) também amplia nossa compreensão quando sinaliza possibilidades para que cada sujeito possa ser reconhecido por suas capacidades e processo de aprendizagem contínuo registrado por sua história e circunstância. Essa postura é interessante especialmente quando nos referimos à questão ambiental, Carvalho (2001, p. 30-31) afirma que:

[...] uma maneira produtiva de compreender a experiência do educador ambiental seria tomá-lo como um intérprete de seu contexto, ao mesmo tempo em que é um sujeito interpretado. [...] Diferentemente de um sujeito-observador, situado fora do tempo histórico, perseguindo os sentidos verdadeiros, reais, permanentes e inequívocos, o sujeito-intérprete estaria diante de um mundo-texto, mergulhado na polissemia e na aventura de produzir sentido a partir de seu horizonte histórico.

As histórias de vida orais dos professores revelam que essas vivências da infância influenciaram suas atitudes e ações atuais instigando-os a 
compreender mais sobre o assunto, dando sentido a sua história social, cultural e ambiental.

[...] A tradição ambiental constitui um território simbólico, uma trama de sentidos e temporalidades sempre reencontrados e recriados nos autoposicionamentos dos sujeitos em suas trajetórias de vida. $\mathrm{O}$ autorelato, nesse sentido, é olocusdesse encontro entre a vida íntima do indivíduo e sua inscrição numa história social, ambiental e cultural (CARVALHO, 2001, p. 71 (grifo nosso).

As histórias de vida orais revelados nas vivências dos professores, mostram a força da reflexão e as possibilidades do auto-conhecimento, eles não narram as coisas conforme aconteceram, mas como as significam e como as percebem.

"O tempo passa e as marcas positivas permanecem comigo desde a idade mais tenra. Assim sendo percebo a importância de trabalharmos tais valores com nossas crianças, para que no futuro sejam melhores e preparados para cuidar da natureza que Deus nos deu." (P1)

Essas marcas positivas podem dar pistas sobre o processo de compreensão da temática ambiental de cada um dos participantes do projeto. A história de vida como estratégia de revisão de suas escolhas e de decisões que foram sendo tomadas. A metodologia da história oral valoriza a memória como fonte de produção de conhecimento "A verdade ou o real nada mais é que uma construção cultural" (SILVEIRA, 2005, p. 2). Assim, todas as participantes da pesquisação têm a possibilidade de ao rever sua história de vida, resgatar uma influência que marcou suas atitudes e relação com o ambiente no qual viveram.

\subsection{ATITUDES CONSCIENTES SOBRE EDUCAÇÃO AMBIENTAL}

Nessa categoria de análise, eixo reflexivo, apresentamos o resgate de algumas histórias de vida orais dos professores que mostram as atitudes atuais que perpassaram o cotidiano escolar e familiar. No ato de narrar à experiência de vida e de lidar com o tempo e espaços vivenciados no passado e presentes no cotidiano os professores têm a possibilidade de se humanizarem deixando 
de ser objetos de uma dada história para se converterem em sujeitos que contam e fazem suas próprias histórias (ABREU, 2000).

As histórias de vida orais a seguir revelam a necessidade de tomada de consciência e uma possível identidade de adesão e defesa pela educação ambiental:

"Eu acho que as pessoas tinham que ter mais consciência, e reciclar mais o lixo, iria diminuir bastante. Fico triste em ver tanta sujeira jogadas por aí, imagino o que passa pela cabeça dessas pessoas, pois há divulgação nas propagandas de TV, nas rádios, na internet, e em todos os lugares, e se cada um fizesse sua parte iria ser bem melhor." (P2)

Para Nóvoa (2007) o processo identitário dos professores compreendem três eixos: a adesão - que se potencializa com a reflexão sobre a educação ambiental do trabalho docente) -; a ação - (que são as escolhas dos professores pela prática ambiental) -; e, a autoconsciência (momento reflexivo da sua ação).

[...] Porque também aqui, na escolha das melhores maneiras de agir, se jogam decisões de foro profissional e de foro pessoal. Todos sabemos que certas técnicas e métodos "colam" melhor com a nossa maneira de ser do que outros. Todos sabemos que o sucesso ou o insucesso de certas experiências "marcam" a nossa postura pedagógica, fazendo-nos sentir bem ou mal com esta ou com aquela maneira de trabalhar em sala de aula (NÓVOA, 2007, p. 16).

A adesão, a ação e a autoconsciência nos impulsionam a perceber as professoras participantes como agentes ambientais que carregam, desde suas infâncias, a gênese da ambientalização curricular. As histórias de vida orais a seguir revelam que a educação ambiental é um experiência pessoal e profissional e que se constitui num processo.

"Ter um cuidado com o outro, nos momentos que interagimos as ações do meio ambiente promovem o bem estar das crianças e as suas experiências do coletivo no espaço escolar". (P4)

"[...] tenho consciência que Educação Ambiental é processual e permanente. Deve estar presente sempre em nosso cotidiano e não "trabalhada" como um projeto com data definida, para cumprir um dos temas transversais, ou para observar a obrigatoriedade da Lei". (P6)

Assim, priorizar as histórias de vida orais, significou também produzir narrativas de identidade, à medida que o sujeito revela como vê o mundo e a si 
mesmo. A história de vida dos professores do CEIM é vista como transformadora e reconstituinte, na medida em que eles tomaram consciência de seus percursos, podendo ressignificar suas experiências, situando-se como agente individual e social do cotidiano escolar. Os participantes da pesquisa são agentes de construção social da questão ambiental e se sentem corresponsáveis pela educação ambiental, como é possível perceber nas histórias de vida orais que seguem:

"[...] começamos a por em prática em minha casa, onde ajudo a separar tudo que se pode aproveitar, desde cascas de frutas e verduras para adubar a lavoura, óleos para fazer sabão, papeis e garrafas pet a serem vendidos para reciclagem, tudo tem seu proveito se soubermos separar, tirando assim do meio em que vivemos tudo aquilo que ajuda a destruir com o meio ambiente". (P6)

"Mas com o aumento da população e a falta de conscientização do povo o planeta terra teve grandes transformações, vindo ocasionar muitos danos a natureza. Obrigando com que as pessoas tenham a preocupação em dar o destino certo do grande acúmulo de lixo pela falta do destino correto, criando projetos de Educação ambiental, reciclagem, compostagem, preservações da natureza, plantios e a preservação da água e seus cuidados. etc... evitando as grandes catástrofes ocorridas na natureza causadas pelo ser humano como retorno dos seus erros cometidos em suas atitudes". (P7)

Ao narrar a história coletiva e a sua história sente-se inserido na problemática ambiental, cada um a seu modo, após reflexão mostra o desejo de defesa da Educação ambiental. Ao retomarem o passado passam a problematizar o futuro e sua profissão. A Educação Ambiental nem sempre esteve presente na escola, é preciso contruir essa relação.

É nítido que os discursos dos professores participantes vêm carregados da ideologia do grupo ao qual pertencem e que revelam o cotidiano no CEIM:

"E quando cheguei aqui no CEIM e vi o trabalho maravilhosos que as mulheres tanto da cozinha quanto da limpeza fazem, tudo é aproveitado as cascas de frutas e verduras tudo vai para a compostagem elas reciclam tudo mesmo, e muito pouco vai para o lixo. Seria bom demais que tivessem em todas as escolas, pois o CEIM (...) pode ser escola modelo, pois está de parabéns." (P2)

"Minhas primeiras experiências sobre esse assunto foram nas escolas em que estudei e no meu local de trabalho, [...] com fortes influências a economizar, preservar e proteger o meio ambiente, usando de atividades voltadas a conscientização". (P3)

"Na escola separamos as pilhas e o óleo de cozinha e as famílias da comunidade trazem para a escola que é entregue para cooperativa." (P5)

"Há 3 anos e meio comecei a trabalhar no CEIM (...) e como a escola faz esse trabalho maravilhoso, com o propósito que é a separação dos resíduos sólidos e orgânicos, comecei à me interessar mais, envolvendo-me ativamente com a separação dos mesmos". (P8) 
As histórias de vida orais indicam a escola como espaço de formação não só para os alunos como também para os professores sobre a questão ambiental. Torna-se fundamental alertar para o fato de que a compreensão sobre a Educação Ambiental e seu significado para a vida de cada professor do CEIM, vem respaldado pela proposta pedagógica assegurada pelo cotidiano da escola.

"Em sala de aula tenho enriquecido minha experiência com as crianças, onde fazemos semanalmente a separação dos resíduos sólidos nas respectivas lixeira, reforçando sempre as cores das mesmas. Realizamos trabalhos pedagógicos com o objetivo de conscientizar nossos pequenos a importância de cuidarmos da natureza, do planeta e mantermos um ambiente adequado para a qualidade de vida." (P3)

"A vivencias ambientais estão presentes no nosso cotidiano com situações investigativas: atividades como horta, compostagem e separação do lixo". (P4)

Podemos considerar que "[...] apesar de todas as fragilidades e ambiguidades, é inegável que as histórias de vida têm dado origem a práticas e reflexões extremamente estimulantes, fertilizadas pelo recurso a uma grande variedade de enquadramentos conceptuais e metodológicos [...]" (NÓVOA, 2007, p. 19), especialmente na área da educação ambiental. As histórias de vida orais acima mostram que não foi necessário criar um espaço para disciplina de educação ambiental(EA), esta é uma questão que emerge da prática cotidiana do CEIM. Aos poucos conceitos foram sendo trabalhados na horta, do lanche, da higiene pessoal das crianças etc. Sinal de que essa compreensão e relação com o ambiente foram sendo construídas.

O CEIM estaria se tornando um espaço ambientalizado? A inclusão do meio ambiente como tema transversal nos Parâmetros Curriculares Nacionais não pode ser entendida como novo conjunto de informações a serem "transmitidos", a prática cotidiana vai mostrando caminhos para ambientalizar a partir da EA e vice e versa conforme orienta o pensamento complexo.

"Quando vim para o CEIM, aprendi a fazer a coisa certa, cascas de frutas e vegetais vão para a compostagem para adubar a horta e as embalagens dos produtos são separadas para o reciclado, que o carro vem pegar uma vez por semana. O lixo aqui no CEIM é bem pouco". (P11)

"Por influência das ações ambientais desenvolvidas no CEIM, estimuladas pela gestora, passei a trazer os resíduos para a escola e começamos a separar com as crianças, pois todas as salas têm as sacolas de TNT nas cores da coleta seletiva. Comecei a solicitar aos alunos,

Criar Educação, Criciúma, v. 6, n², julho/novembro 2017.- PPGE - UNESC 
como tarefa que trouxessem os resíduos recicláveis para a separação em sala de aula, e isso se tornou prática permanente em meu planejamento". (P12)

Essas escolhas pedagógicas foram essenciais para a tomada de posição consciente em relação ao ambiente. Assim, os professores desvelam por sua narrativa um lugar que indicava atenção, disponibilidade para aprender e cuidar do espaço de trabalho. "[...] É evidente que a pessoa que mais sabe de uma dada trajetória profissional é a pessoa que a viveu. Do mesmo modo, a maneira como essa pessoa define as situações com que viu confrontada desempenha um papel primordial na explicação do que se passou". (HUBERMAN, 2007, p. 55). O processo educacional sofre modificação e favorecem o desenvolvimento profissional porque aprendemos uns com os outros. Numa mesma medida, o desenvolvimento pessoal é nutrido pelas relações que se estabelecem.

\section{CONSIDERAÇÕES FINAIS}

A pesquisação funcionou como uma prática pedagógica ao promover momentos diferenciados e complementares de reflexões sobre a prática e de conteúdos para a renovação da prática e dos desafios cotidianos. A história de vida oral retomada pelos professores do CEIM, promoveu discussões e reflexões necessárias à Educação Ambiental de forma articulada à Educação para a Inteireza contribuindo com o processo de desenvolvimento pessoal e profissional daqueles professores.

A importância desse estudo está na compreensão de que que o processo de Ambientalização Curricular nas escolas depende de um espaço relacional, de vivência, de troca de experiências, de histórias orais de vidas compartilhadas para que se possa construir um verdadeiro aprendizado sobre a relação do homem com o ambiente.

Incentivar reflexões sobre o tema no CEIM, de forma intencional, possibilitou aos professores a revisão de seus próprios caminhos e a compreensão de que o aprendizado é contínuo rumo a uma consciência de que "todo ato de conhecer produz um mundo" (MATURANA; VARELLA, 1995, p. 
60), tendo em vista a inseparabilidade entre ação e experiência, entre conhecer e fazer.

Consideramos provisoriamente que os encontros pedagógicos promoveram a compreensão da relação entre Educação Ambiental, Ambientalização e Educação para a Inteireza contribuindo para com o processo de desenvolvimento pessoal e profissional daqueles professores. $\mathrm{E}$ nessa aventura reflexiva, os professores puderam pensar num outro modelo de formação integral capaz de privilegiar o reconhecimento do caráter multidimensional do humano.

\section{REFERÊNCIAS}

ABREU, R.Subjetividade, alteridade e memória social em Ruth Landes. In: XXIV ENCONTRO ANUAL DA ANPOCS - Associação Nacional de PósGraduação e Pesquisa em Ciências Sociais - GP 1 "Memória social e biografias", Petrópolis. 2000.

ANDRADE, Izabel Cristina Feijó de. A inteireza do ser : uma perspectiva transdisciplinar na autoformação de educadores . tese. Porto Alegre, 2011. $213 \mathrm{f}$.

ARRUDA M. P.; LOCKS, GA ; PAGLIOSA, F . Estratégia de educação permanente em saúde como possibilidade de intervenção social. Perspectivas. Notas Sobre Intervención y Acción Social, v. 1, p. 23-33, 2009. Editora da Universidade do Chile.

BRASIL. Ministério da Educação. Conselho Nacional de Educação - CNE. Resolução n. 2, de 15 de junho de 2012. Estabelece as Diretrizes Curriculares Nacionais para a Educação Ambiental. Brasília: MEC/CNE, 2012.

BEHRENS, Marilda Aparecida. Formação continuada dos professores e a prática

pedagógica. Curitiba: Champagnat, 1996.

. Paradigma da complexidade: metodologia de projetos, contratos didáticos e portfólios. Petrópolis - RJ: Vozes, 2006.

BOSI, E. O tempo vivo da memória. São Paulo: Ateliê Editorial, 2003.

CARVALHO, I. C. M. A invenção ecológica: narrativas e trajetórias da educação ambiental no Brasil. Porto Alegre: Editora da UFRGS, 2001.

JOSSO, Marie Christine. Experiências de vida e formação. Tradução de José Claudio, Julia Ferreira. 2 ed. ver. e ampl. Natala, RN: EDUFRN; São Paulo: Paulus, 2010.

LEFF, E. Saber Ambiental. Petrópolis-RJ: Vozes, 2001. 
MATURANA, H.; VARELLA, F. A árvore do conhecimento: as bases biológicas do

entendimento humano. São Paulo: Psy II, 1986. MOITA, Maria da Conceição. Percursos de formação e de transformação. In.: NÓVOA, Antonio (org.). Vidas de professores. 2. ed. Porto: Porto Editora, 2007. p. 111-140.

MORIN, Edgar. Os sete saberes necessários à educação do futuro. 8 ed. São Paulo: Cortez; Brasília: UNESCO, 2003.

MORIN, E. O Método 5 - A humanidade da humanidade: a identidade humana. Porto Alegre: Sulina, 2001.

Sulina, 2010.

. Introdução ao pensamento complexo. 3. ed. Porto Alegre:

NÓVOA, A. O regresso dos professores. Conferência: Desenvolvimento profissional de professores para a qualidade e para a equidade da Aprendizagem ao longo da vida. Presidência Portuguesa do Conselho da União Européia. Lisboa, 27 e 28 de Setembro de 2007.

PORTAL, L.L.F.O sentido da existência humana: um olhar para cima na aventura do encontro interior. In: ENRICONE, Délcia (Org.). A docência na educação superior, sete olhares. Porto Alegre: Evangraf, 2006. p. 45-58.

in MOROSINI, Marília C. Enciclopédia de Pedagogia

Universitária Glossário. Volume 2. Brasília: Instituto Nacional de Estudos e Pesquisas Educacionais Anísio Teixeira., 2006

PORTO, Y.S. Formação continuada: a prática pedagógica recorrente. In: MARIN, A.J. (Org.). Educação continuada: reflexões e alternativas. Campinas:Papirus, 2000. p.11-38.

REDE ACES. Red de Ambientalización Curricular de losEstudios Superiores. 2002.

Disponível em: <http://insma.udg.es/ambientalitzacio/web_alfastinas/castella/c_index.htm>.

Acesso em:14 dez. 2013.

SILVEIRA, Éder da Silva. História oral e memória: a construção de um perfil de historiador-etnográfico. Ciência e Conhecimento - Revista Eletrônica da Ulbra São

Jerônimo, v. 01, 2007, História, A.2 Disponível em: <

http://www.cienciaeconhecimento.com >. Acesso em: 14 dez. 2014.

TARDIF, Maurice. Saberes docentes e formação profissional. 5. ed. Petrópolis: Vozes, 2005.

THIOLLENT, M. Pesquisa-ação nas organizações. São Paulo: Atlas, 1997. WILBER, K. Uma teoria de tudo: uma visão integral para os negócios, a política, a ciência e a espiritualidade. São Paulo: Cultrix, Amaná-Key, 2007.

Professora e pesquisadora dos Programas de Pos-graduação em Educação (PPGE) e Ambiente e Saúde(PPGAS) da Universidade do Planalto Catarinense - UNIPLAC. 
Professora e pesquisadora dos Programas de Pos-graduação em Educação (PPGE) e Ambiente e Saúde(PPGAS) da Universidade do Planalto Catarinense - UNIPLAC.

2. A Educação Permanente se apresenta como uma "estratégia de ação" e a Educação Continuada como "programa ou espaço de retomada de conteúdos, conceitos importantes para a retroalimentação" da prática. Ver discussão desenvolvida por Arrudaet all, 2008. 